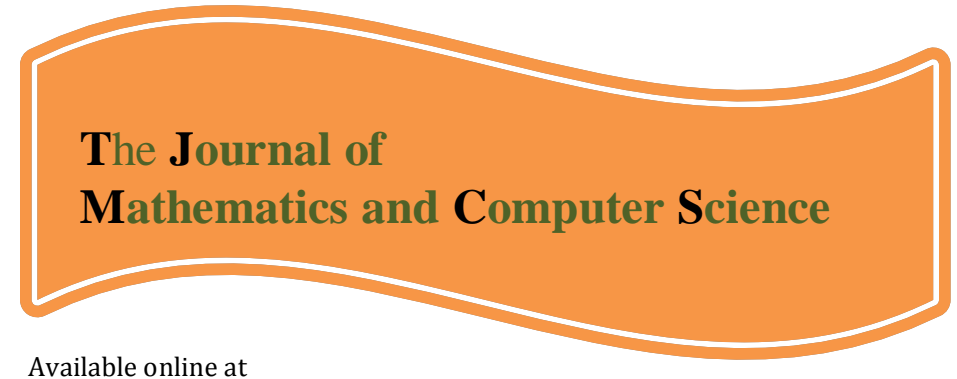

Available online at

http://www.TJMCS.com

The Journal of Mathematics and Computer Science Vol .2 No.4 (2011) 572-579

\title{
Robust Control of DC motor Using Fuzzy Sliding Mode Control and Genetic Algorithm
}

\author{
Mahbubeh Moghaddas', MohamadReza Dastranj' ${ }^{2}$, Nemat Changizi ${ }^{3}$, Modjtaba Rouhani $^{4}$ \\ Islamic Azad University Gonabad Branch, Iran, Moghaddasm.m@gmail.com \\ Islamic Azad University Gonabad Branch, Iran, Mohamadrezadastranj@gmail.com \\ Islamic Azad University Gonabad Branch, Iran, Nemat.changizi@gmail.com \\ Islamic Azad University Gonabad Branch, Iran, M.rouhani@ieee.org
}

Received: August 2010, Revised: November 2010

Online Publication: January 2011

\begin{abstract}
Wide amplitude, DC motor's speed and their facile control cause its great application in industries. Generally the DC motors gain speed by armature voltage control or field control. In this paper, by using a combination of Fuzzy Sliding Mode methods and Genetic Algorithms, we have tired to optimally control the inverted pendulum by nonlinear equations. The results of this simulation have been mentioned in the conclusion. It seems that the results be acceptable results.
\end{abstract}

Keywords: Nonlinear control, Optimal, classical PID controller, Genetic Algorithm

\section{Introduction}

There are variety methods for DC motors control that are presented since now. The presented methods for DC motors control are divided generally in three groups. Classic methods such as PID and PI

1, MSC Student Islamic Azad University Gonabad Branch, Iran

2, MSC Student Islamic Azad University Gonabad Branch, Iran

3, MSC Student Islamic Azad University Gonabad Branch, Iran

4,Assistant Professor Islamic Azad University Gonabad Branch, Iran 
controllers [1,2]. Modern methods (adaptation-optimum...) [3, 4, 5] .Artificial methods such as neural networks and fuzzy $[6,7]$ Theory are the presented methods for DC motors speed control.

The design method in linear control comprise based on main application the wide span ' of frequency, linear controller has a weak application, because it can't compensate the nonlinear system effect completely.

\section{Model of DC Motor}

The direct current motors are different kinds and several methods are presented for controlling of their speed. In this essay DC motor was chosen for speed control and by controlling the supply voltage was controlled it in nominal less speed.

The electric circuit of the armature and the free body diagram of the rotor are shown in fig. 1

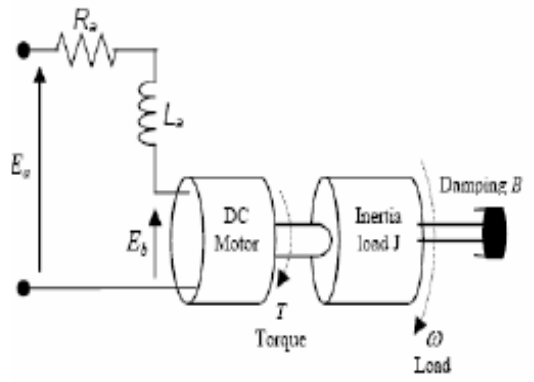

Figure 1: The structure of a DC motor

$V_{t}=R_{a} I_{a}+L_{a} \frac{d I_{a}}{d t}+E_{a}$

$\mathrm{T}=\mathrm{J} \frac{\mathrm{d} \omega}{\mathrm{dt}}+\mathrm{B} \omega-\mathrm{T}_{\mathrm{i}}$

$\mathrm{T}=\mathrm{K}_{\mathrm{T}} \mathrm{I}_{\mathrm{a}}$

$\mathrm{E}_{\mathrm{a}}=\mathrm{K}_{\mathrm{a}} \omega$

$\frac{\mathrm{d} \omega}{\mathrm{dt}}=\varphi$

With the following physical parameters:

Ea: The input terminal voltage (source), (v);

Eb: The back emf, (v);

Ra: The armature resistance, (ohm);

Ia: The armature current (Amp);

La: The armature inductance, $(\mathrm{H})$;

J: The moment inertial of the motor rotor and load,(Kg.m2/s2);

T: The motor torque, (Nm)

$\mathrm{w}$ : The speed of the shaft and the load (angular velocity),(Rad/s);

f : The shaft position, (Rad);

B: The damping ratio of the mechanical system, (Nms);

$\mathrm{T} \mathrm{k}$ : The torque factor constant, (Nm/Amp); 
B k: The motor constant ( $\mathrm{v}-\mathrm{s} / \mathrm{rad})$.

Block diagram of a DC motor is shown in fig. 2 [8].

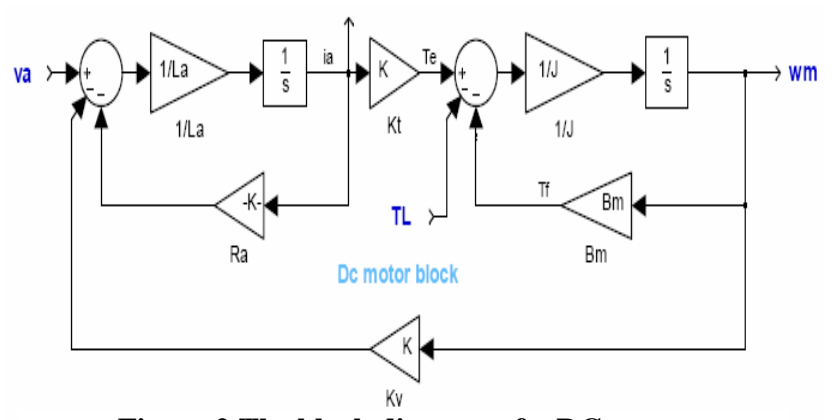

Figure 2.The block diagram of a DC motor

At first we control the DC motor by PID controller in fig.3

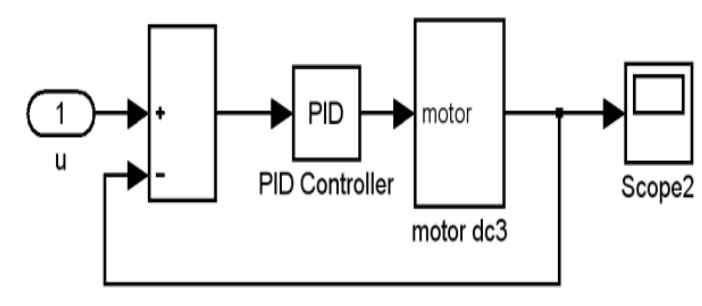

Figure 3.The block diagram of a PID controller dc motor

The results are based on fig.4

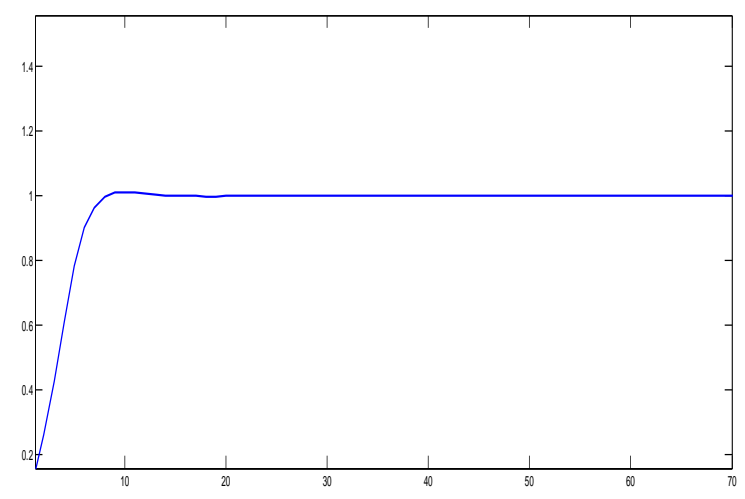

Figure 4.Simulated results PID controller of DC motor

The step response is proportionately a good response. Now with this controller we examine the step response of DC motor with uncertainly.(fig 5) 


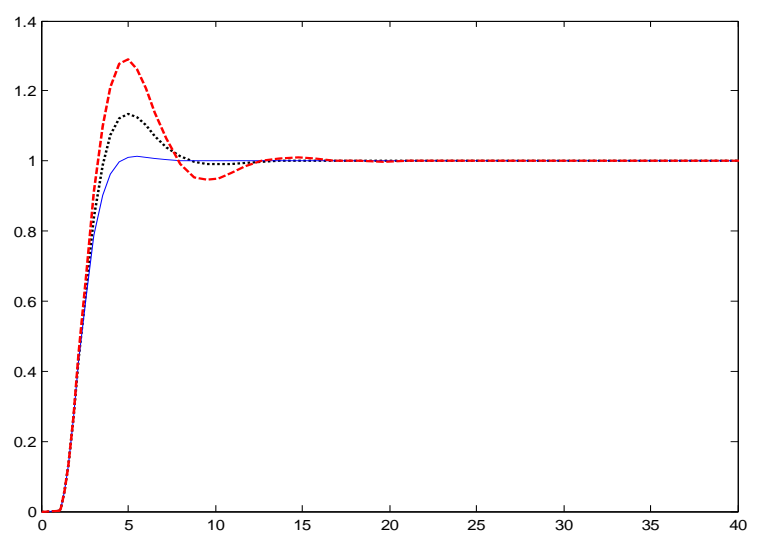

Figure 5.Simulated results PID controller of DC motor with uncertainties

You can see that the system's response to uncertain motor is not proper response.

\section{Sliding Mode Controller}

Nonlinear system control that its model isn't clear carefully works with tow methods:

(1).Robust control methods.

(2).Adaptive control methods.

In control view, uncertainly in modeling is divided in two main kinds:

(1).Non certainly in existent Parameters in model

(2).Estimating the lower step for system and being UN modeled dynamics in the estimating model.

Sliding control is one of the designed modes for robust control that make access to system desired application estimating system in model.

The major idea of this method is the controlling of nonlinear first grade system is easier than $\mathrm{n}$ grade system control in spite of uncertainly.

But this function maybe cause the control law with more energy that is not practicable implement station. Sliding mode is really compromise between modeling and suitable operation with inaccurate design.

We consider the non linear system model in this rule:

$X^{n}=f(x)+b(x) u$

That $\mathrm{F}(\mathrm{x})$ is nonlinear function, its high boundary characterized as $\mathrm{X}$ function. $\mathrm{B}(\mathrm{x})$ is a continuous function that its high and low boundaries characterized by $\mathrm{X}$ function.

The good of finding $\mathrm{X}$ is in this way that in $\mathrm{g}(\mathrm{x}) \mathrm{F}(\mathrm{x})$ function we can follow the desirable mode in spite of uncertainly. 
$\widetilde{X}=X-X_{d}=\left[\tilde{X}, \widetilde{X}^{t}, \ldots, \tilde{X}^{n-1}\right]$

In ideal state

$\tilde{X}=0$

Sliding surface equation defines as below:

$s=e^{\prime}+\alpha_{1} e+\alpha_{2} \int e d t$

Because of the signals of control that gain with this designing method has limited energy, it is necessary to:

$X_{d}(0)=X(0)$

In other word:

$S(X, t) \equiv 0$

$\frac{1}{2} \frac{d S^{2}}{d t} \leq-\eta|S|$

In designing, the control low on $\mathrm{S}(\mathrm{t})$ continuously is noticed cause we should concentrate to carelessness in model in sliding surface and reduced the chattering effect.

We can write the system's dynamics when in some situation they are in sliding state.

$S^{\prime}=0$

The gained control signals for this system are as below:

$U=k_{1} \times$ out $_{f u z z y} * S$

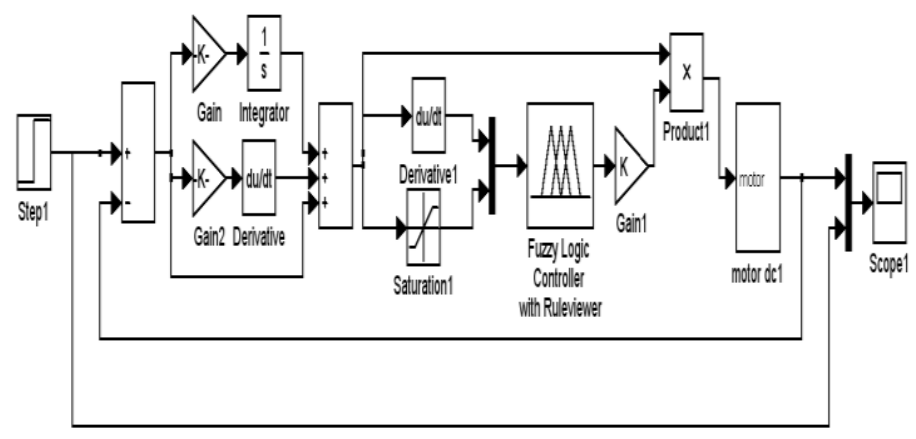

Figure6.simulink block diagram of FSMC

Fuzzy controls are designed based on created sliding surface and sliding surface changes. All of the fuzzy rules collection came in Table II 


\begin{tabular}{|l|l|l|l|l|l|}
\multicolumn{7}{|c|}{ Table2. Fuzzy Rule } \\
\hline dS / S & NB & NS & ZE & PS & PB \\
\hline N & B & B & M & S & B \\
\hline Z & B & M & S & M & B \\
\hline P & B & S & M & B & B \\
\hline
\end{tabular}

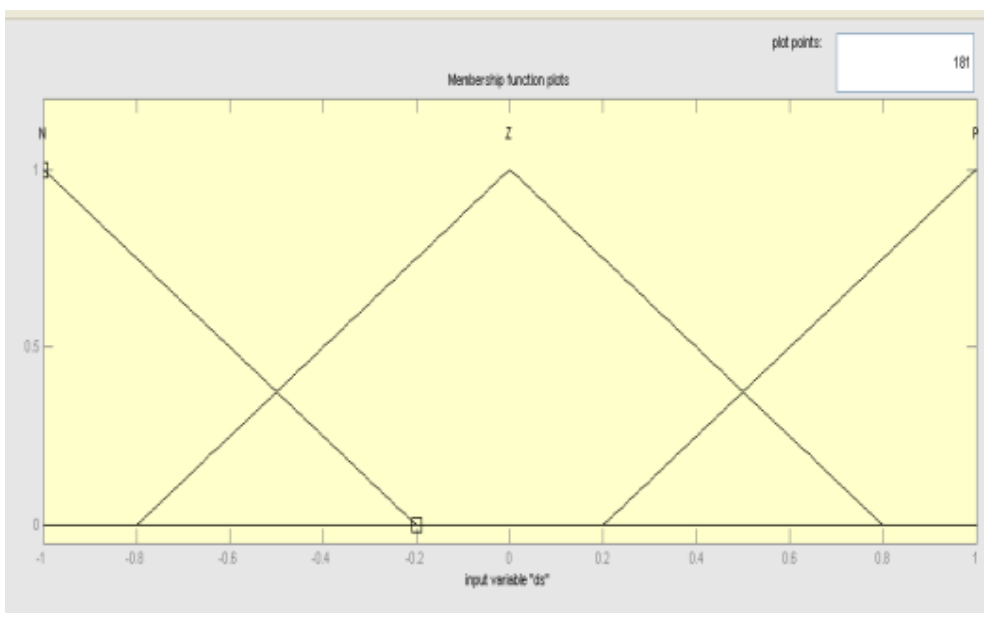

Figure 7.Membership functions for (ds/dt) normalized inputs

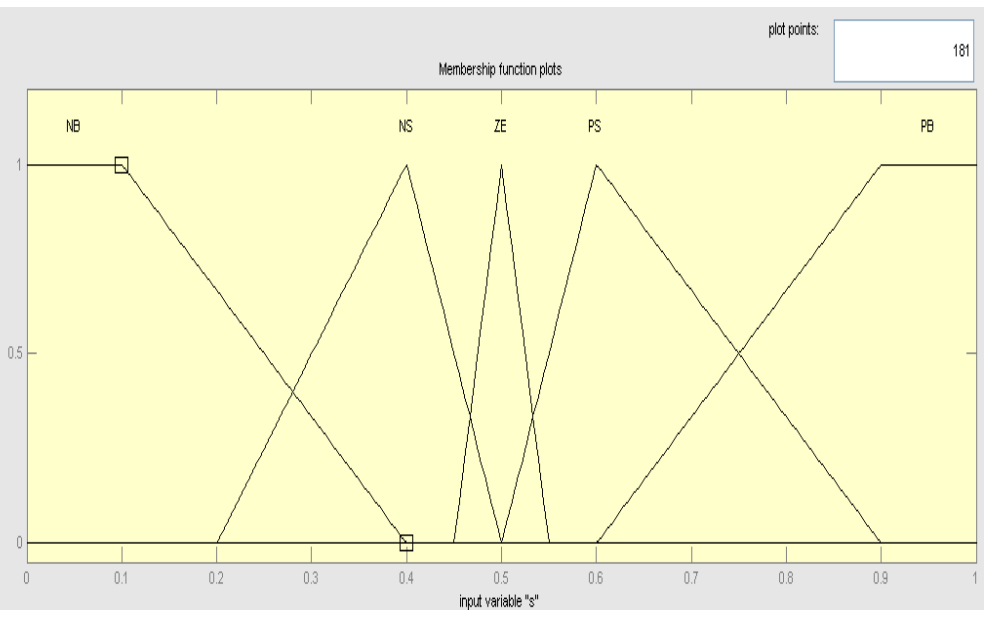

Figure 8.Membership functions for (ds/dt) normalized inputs

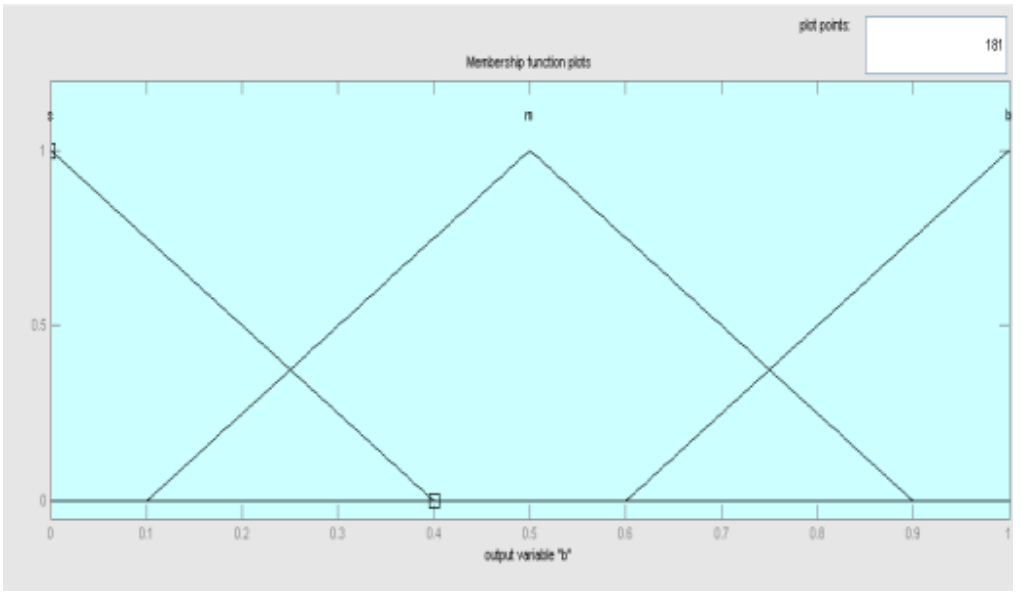

Figure 9.Membership functions for (out fuzzy) normalized outputs

\section{Genetic Algorithm}

Genetic algorithms are developed by Prof. Holland $[5,6]$. This methodology is a derivative free optimization technique based on the concept of natural selection and evolution processes. The genetic operations are reproduction, crossover and mutation.

The evolution procedure of GAs is shown in Fig. 7. Producing initial populations is the first step of GAs. The population is composed of the chromosomes that are binary bit string or real codes. The 
corresponding valuation of a population is called the "fitness function". It is the performance index of a population. The fitness value is bigger, and the performance is better. The fitness function is defined as follow:

PI $=$ MIN - offset -

$\sum \mid \mathrm{el}$

Where "PI" is the fitness value, e is the speed error and "offset_MIN" is a constant.

After the fitness function is calculated, the fitness value and the number of the generation determine whether the evolution procedure is stopped or not. In the following, the new populations are generated through reproduction, crossover and mutation. The selection operation decides which parents take part in reproducing offspring for the next generation. The crossover operation is applied to generate new chromosomes. The equations of the new populations generated from crossover are:

$\mathrm{X}_{01}=(1-\beta) \mathrm{X}_{\mathrm{p} 1}+\beta \mathrm{X}_{\mathrm{p} 2}$

$\mathrm{X}_{02}=\beta \mathrm{X}_{\mathrm{p} 1}+(1-\beta) \mathrm{X}_{\mathrm{p} 2}$

Where xp1 and xp2 are the old chromosomes, $\beta$ is the random value from 0 to $1, x 01$ and $x 02$ are the new chromosomes. Mutation is a method to find the global optimal values. It changes the chromosomes from a random value.

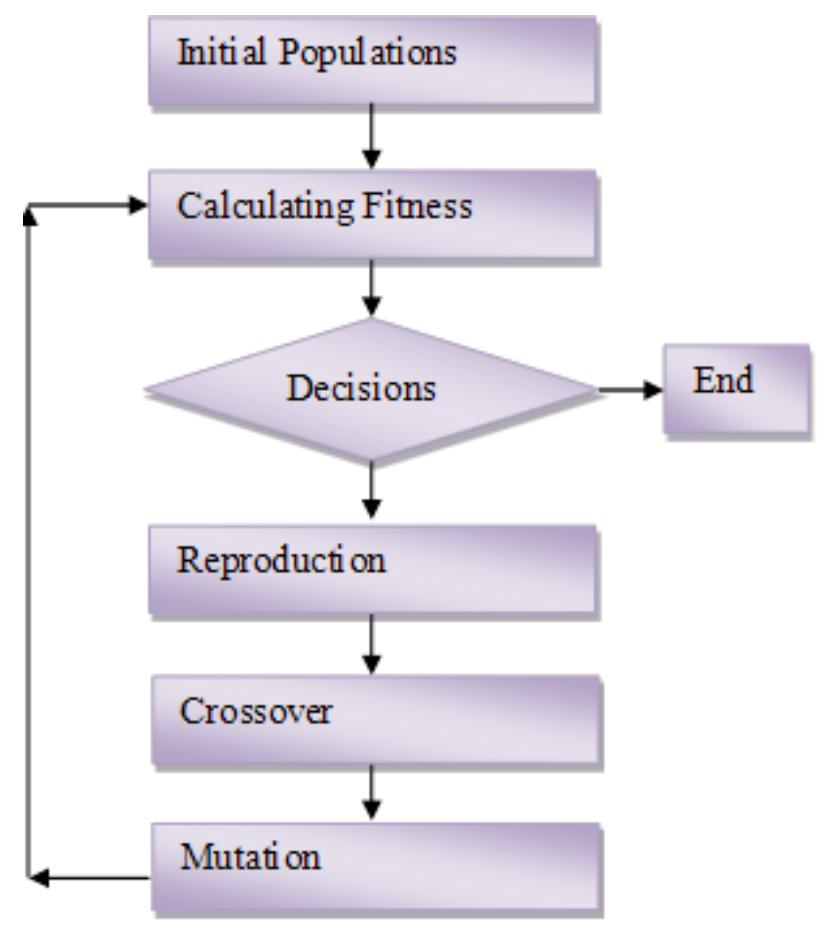

Figure 7.The evolution procedure of GAs

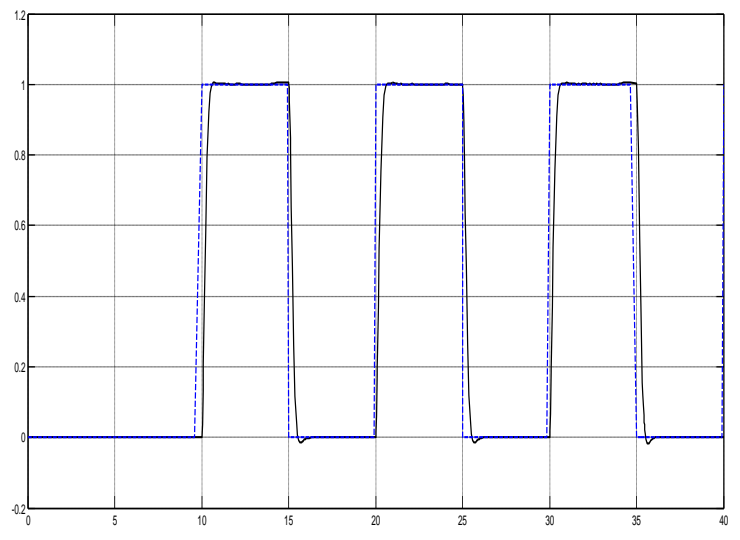

Figure 6.Simulated pulse results FSMC of DC motor

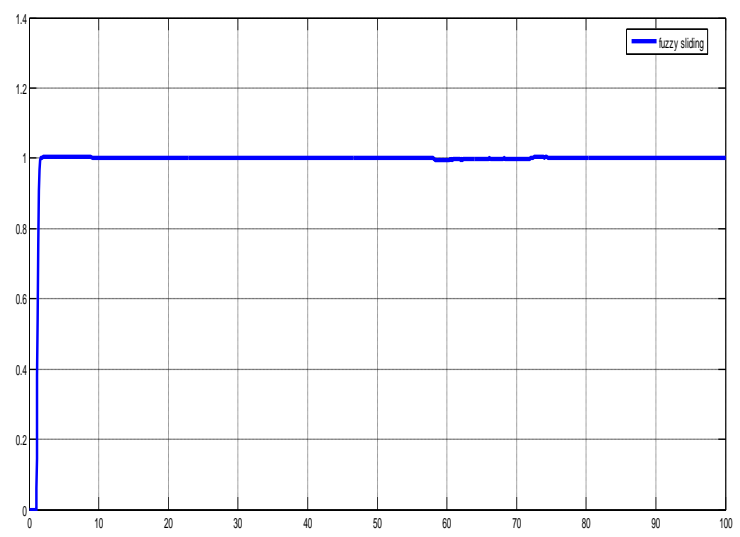

Figure 8.Simulated step results FSMC of DC motor 


\section{Conclusion}

In this paper, a robust control system with the fuzzy sliding mode controller and the additional compensator is presented for a DC motor position control. According to the simulation results, the FSMC controllers can provide the properties of insensitivity and robustness to uncertainties and external disturbances, and response of the DC motor for FSMC controllers against uncertainties and external disturbance is the same Fuzzy sliding mode controller gives a better response to system than the fuzzy and classical PID controllers. If $\alpha_{1}, \alpha_{2}, \mathrm{k}_{1}$ control parameters set suitably

\section{References}

[1].Paul I-HaiLin,Santai Hwang and John Chou, "COMPARISON ON FUZZY LOGIC AND PID CONTROLS FOR A DC MOTOR POSITION CONTROLLER" Indiana-Purdo University Fort Wayne. [2]. J.Tang and R.Chassaing, "PID Controller Using theTMS320C31 DSK for Real-Time DC Motor Control" Proceedings of the 1999 Texas Instruments DSPS Fest, Houston, Texas, August 1999 [3].Y.P. Yang, C.H. Cheung, S.W. Wu, J .P Wang "OPTIMAL DESIGN AND CONTROL OF AXIAL-FLUX BRUSHLESS DC WHEEL MOTOR FOR ELECTRICAL VEHICLES" Proceedings of the 10th Mediterranean Conference on Control and Automation - MED2002 Lisbon, Portugal, July 9-12, 2002.

[4]Hyun Cheol Cho, Kwon Soon Lee and Sami M. Fadali REAL-"TIME ADAPTIVE SPEED CONTROL OF DC MOTORS WITHBOUNDED PERIODIC RANDOM DISTURBANCE" ICIC International ${ }^{\circ} \mathrm{C} 2009$ ISSN 1349-4198.

[5].M.Fallahi, Member, IAENG, S.Azadi, Member, IAENG. "Adaptive Control of a DC Motor Using Neural Network Sliding Mode Control" Proceedings of the International MultiConference of Engineers and Computer Scientists 2009 Vol II IMECS 2009, March 18 - 20, 2009, Hong Kong [6]Jang J. S. R. Adaptive network based fuzzy inference systems. IEEE Transactions on systems man and cybernetics 1993 , p. 665-685.

[7]Boumediene ALLAOUA*, Abdellah LAOUFI, Brahim GASBAOUI, and Abdessalam ABDERRAHMANI "Neuro-Fuzzy DC Motor Speed Control Using Particle Swarm Optimization' 'Issue 15, July-December 2009

[8]. M.Fallahi, Member, IAENG, S.Azadi, Member, IAENG."Robust Control of DC Motor Using Fuzzy Sliding Mode Control with PID Compensator" Proceedings of the International Multi Conference of Engineers and Computer Scientists 2009 Vol II IMECS 2009, March 18 - 20, 2009, Hong Kong J.Tang and R.Chassaing, 